\title{
A Bargaining Game Analysis of International Climate
}

\author{
Negotiations $^{*+*}$ \\ Rory Smead (Northeastern University) \\ Ronald L. Sandler (Northeastern University) \\ Patrick Forber (Tufts University) \\ John Basl (Northeastern University)
}

\footnotetext{
${ }^{*}$ Correspondence and requests for materials should be addressed to r.smead@neu.edu.

' We would like to thank the editors at Nature Climate Change as well as two anonymous reviewers for helpful comments on a previous draft of this manuscript.

${ }^{\ddagger}$ RLS and RS oversaw the project. RS and PF developed the models and ran simulations. RLS and JB analyzed the status of current climate negotiations and policy. RLS, RS, PF, and JB jointly developed how to apply the model to climate negotiations, derived general recommendations, and wrote the paper.
} 
Climate negotiations under the United Nations Framework Convention on Climate Change (UNFCCC) have so far failed to achieve a robust international agreement to reduce greenhouse gas emissions. Game theory has been used to investigate possible climate negotiation solutions and strategies for accomplishing them [1]. Negotiations have been primarily modelled as public goods games such as the Prisoner's Dilemma [2], though coordination games or games of conflict have also been used $[3,4]$. Many of these models have solutions, in the form of equilibria, corresponding to possible positive outcomes - that is, agreements with the requisite emissions reduction commitments $[5,6]$. Other work on large-scale social dilemmas suggests that it should be possible to resolve the climate problem [7-9]. It therefore appears that equilibrium selection [10] may be a barrier to successful negotiations. Here we use an $\mathrm{N}$-player bargaining game in an agent-based model with learning dynamics to examine the past failures of, and future prospects for a robust international climate agreement. The model suggests reasons why the desirable solutions identified in previous game-theoretic models have not yet been accomplished in practice and what mechanisms might be used to achieve these solutions.

Many models of climate negotiations attempt to capture a wide range of realistic features of the climate problem so as to achieve descriptive accuracy; studies based on the Stability of Coalitions model exemplify such an approach [11-16]. Focusing instead on the dynamical behaviour of a simple bargaining game, we are able to identify possible barriers (and solutions) that may be hidden by more complex models. Most game-theoretic studies on the climate problem ask whether stable solutions exist, but relatively few use evolutionary or learning dynamics to explore whether they are achievable. Such approaches consider the way that imperfect agents may adapt to each other's behaviour and how this affects the chance of 
reaching solutions [19]. We model the learning dynamics in the context of bargaining over an allotment of a fixed emission total.

We use a modified version of the Nash bargaining game [19] with $\mathrm{N}$ players representing the negotiating countries or coalitions. Each player's strategy set is the interval $[0,1]$ representing the range of possible reductions: 1 representing the 'business as usual' (BAU) 100\% emissions, and 0 representing no emissions. Let $d_{i}$ correspond to a player's demand for some proportion of their BAU emissions (equivalently, this represents their proposed reduction). Players may also differ in size and similar demands from larger players will mean more emissions. Let $s_{i}$ represent the size of a player and $t=\Sigma_{i} d_{i} s_{i}$ represent the total of all demands made adjusting for the size of the players.

Suppose there is also a target value $\mathrm{T}$ that must be met if a set of demands is to constitute a successful solution. $\mathrm{T}$ is a global reduction goal ranging from 0 to 1 representing the global reduction necessary for an agreement as a proportion of business as usual. For a given set of demands from all players the payoff to each of them is defined as:

$$
\pi_{i}\left(d_{i}, t\right)=\left\{\begin{array}{l}
d_{i} \text { if } t \leq T \sum_{i} s_{i} \\
\delta d_{i} \text { if } t>T \sum_{i} s_{i}
\end{array}\right.
$$

If the target value is reached, the demand set is viewed as successful and a possible agreement. The perceived payoff in this case is equal to the amount of the shared resource demanded. If the target is not met, the payoff is devalued by a factor of $0<\delta<1$, which represents the importance of reaching an agreement. Lower $\delta$ means the more payoffs are devalued in the event of non-agreement. The payoff function represents the perceived payoff of making a particular demand given the demands of others. The payoff function implies that players will always favour demands closer to their BAU strategy unless increasing their demands threatens to collapse a potential agreement. 
The original Nash bargaining game had only two players, each making a single demand, and had fixed disagreement payoffs. Analysis of this game has traditionally taken the form of identifying specific preferred solutions that satisfy different sets of requirements [20,21]. Other bargaining studies have considered the effects of introducing additional strategic complexities $[22,23]$. Our approach retains much of the simplicity of the original game and focuses on the challenge that learners face during bargaining [24].

To represent adaptive agents within the context of negotiations, we will consider a sequence of simultaneous demands made by each agent, where each demand is visible to all agents. Agents may learn during the negotiations and change their demand between each round of negotiation. We will model the learning process using a variation of simultaneous fictitious play - agents form expectations about the other players' demands based on past behaviour and respond by making a demand that maximizes payoff given these expectations [25-27]. Traditional fictitious play forms expectations of others' choices by assuming they are randomizing among observed strategies in a fixed way. In our model, however, agents form expectations by determining the mean of others' previous demands (see the supplementary information, SI, for comparison of this and the traditional approach). In each round, each agent makes a demand to maximize her return given the anticipated demands of others. The resulting state is a product of the interdependent individual choices. Initial demands are randomly chosen among those that agents are willing to consider; any $\mathrm{d}_{\mathrm{i}}<\delta$ is excluded. Note that agents are not aware feasible solutions are possible until they observe a combination of demands such that an individual adjustment could reach the target value. Feasible solutions are sets of demands that are (i) at or under the target value and (ii) constitute an equilibrium situation where no player can do better by demanding more or less. Such solutions exist whenever the target value is at least as large as the sum of the minimum demands. If this condition is met, any set of strategies such that $\mathrm{t}=\mathrm{T} \Sigma_{\mathrm{i}} \mathrm{S}_{\mathrm{i}}$ is a strict Nash 
equilibrium of the game, and no player can deviate from these states without making themselves worse off (see Proposition 1 in the SI). Consequently, a feasible solution will be stable if it is reached in negotiations. What is not clear, however, is whether agents can reliably reach such solutions.

Even if there are feasible solutions there may be other possible outcomes that are less desirable. In particular, it is possible for negotiations to break down and for everyone to opt for their BAU strategy. If the distance between the target and the sum of the maximum demands is greater than what any one player can reduce, disagreement equilibria exist. Moreover, these disagreement equilibria also constitute strict Nash equilibria of the game and thus can be possible outcomes for adaptive agents in the game (see Proposition 2 in the SI). Therefore, the game includes a potential obstacle to successful negotiations that is not related to stability of feasible solutions: whether learners can find these solutions and avoid disagreement equilibria.

We used computer simulations to determine whether agents that learn during negotiations can find feasible solutions and how likely they are to reach these solutions. These simulations also allow us to assess the effects of changes in the bargaining situation. In what follows, we will assume a target value of $\mathrm{T}=0.5$ representing a goal of reducing emissions to $50 \%$ of BAU. Higher target values make agreement easier and lower target values make agreement more difficult. Suppose that any negotiations that get within $1 \%$ of the target value within 100 rounds count as a success. Simulations reveal that both feasible solutions and disagreement equilibria are observed and that players typically converge on equilibria quickly. In a typical negotiation, agents will begin with widely dispersed demands and react strongly to early rounds before converging on either a feasible solution or the disagreement equilibrium (Fig. 1). 
There are a variety of factors that affect the chance of success. One such factor is the number of players. While negotiations can produce both agreement and disagreement equilibria with any number of players, the chance of successful negotiation dramatically decreases as the number of players increases (Fig. 2).

The discount factor for disagreement outcomes can also substantially impact the chance of reaching a successful agreement. The higher $\delta$, the higher the minimum acceptable demand is for each player. Higher minimum demands means higher average initial demands as well as more constraints on the sets of demands that can constitute successful agreements.

Heterogeneity of the size of players has a positive impact on reaching an agreement. As a subset of players is made larger, the success rate for negotiations increases (Table 1). The reason that heterogeneity helps to reach a positive solution is that it introduces some constraints on the dynamics; games with less flexible players resemble games with fewer players. Examining cases with players of varying sizes also reveals that successful negotiations tend to be those where the larger players make proportionally larger concessions (Table 2). Since larger players have a larger impact on total emissions, adjustments on their part tend to make up a more substantial part of reaching the reduction target. Players responsible for larger shares of global BAU should expect to make larger proportional reduction commitments in successful negotiations.

The initial starting point of the negotiation process is crucial to the end result. If too many players start with very high demands, negotiations usually break down. The reason for this is that the further above the target the total demands are, the more collective action it takes to reach the target. While the result is intuitive it has an important moral: any mechanism that encourages initial demands that are closer to the target value will increase the chance that an agreement is reached. Introducing restrictions on initial demands to limit their size has a 
positive effect on the success of negotiations. This positive effect can be enhanced by also restricting minimum initial demands (Fig. 3). Restricting both maximum and minimum initial demands improves the success rate by ensuring both reasonable starting demands and flexibility in future rounds of negotiation.

We can also represent the possibility of side-deals, or reduction agreements made before the bargaining process. To do this, we reduce the maximum possible demand for one or more players thus restricting the strategy space for those players. This will have the effect of reducing, on average, the players' initial demands as well as constraining their maximum demands during the negotiation process. Such prior reductions can have a dramatic impact on the likelihood of successful negotiations. Examining prior reductions in cases with agents of different sizes also reveals some interesting effects. For instance, a prior reduction from a large number of smaller players is better than an equivalent reduction from a small number of larger players (Table 3). This suggests that prior agreements among smaller players can be more important for success than similar prior agreements from larger players. However, if these prior reductions are accompanied by higher minimum demands, perhaps because players that make prior reductions feel entitled to higher demands during negotiations, then the success rate tends to decline. Prior reductions - constraints on maximum demands - will be less effective or counter-productive if they are accompanied by constraints on minimum acceptable demands.

Our model addresses the possibility that the problem in reaching an international climate agreement is not one concerning the existence of successful solutions but of realizing them in negotiation. It captures two important features of international negotiations simultaneously: distribution and coordination. A successful agreement requires coordination in the form of compatible demands, but all players also have an incentive to reduce emissions as little as possible. The idealizations and simplicity of the model mean that lessons for policy 
recommendations should be treated with caution [27]. Nevertheless, insofar as the model captures the core of continuing negotiations, we have identified some potential difficulties for international climate agreements as well as possible ways to address these difficulties.

There are sufficient interactions within the UNFCCC process to satisfy the learning conditions in the model, which is itself applicable to both Kyoto-style grand bargain approaches and Copenhagen-style collaborative reduction approaches to reaching an agreement. In both cases, parties observe the declarations of others and respond with their own declarations. Thus, the model is neutral on the process for how reduction commitments are made: merely altering the mechanism is unlikely to change the outcome. It also suggests that when positive outcomes are reachable, they are achieved relatively quickly. Such considerations imply that unless the conditions of the UNFCCC negotiations change dramatically, future success is doubtful. However, the model indicates ways in which the chances of a successful agreement could be improved.

First, the large number of players (countries) involved in the negotiations appears to present a significant barrier to a positive outcome from the negotiation process. However, introducing the right kind of constraints on players can improve the prospects for agreement. For example, if the United States and China were to reach a bilateral reduction agreement outside of the UNFCCC, which they then brought into the negotiation, the chance of success increases. Indeed, any players, large or small, can do a service to the process by making agreements outside of it - and reaching side agreements should be relatively easy precisely because they involve just a few players. Rather than undermining the UNFCCC process, additional negotiation venues could help facilitate a broader international agreement [28-29]. In fact, it seems that prior commitments from a larger number of smaller emitters can be more important than similar commitments from fewer larger emitters. An important proviso is that reduction commitments accompanied by increased constraints on the minimum 
acceptable share of emissions can make negotiations harder. External commitments and side agreements need to be made in a way that constrains the maximum demands but does not 'lock in' higher minimum demands.

The model also suggests that the likely outcome of negotiations is sensitive to initial demands. If too many players are too far away from their proportional share of reductions, negotiations are likely to break down. Any mechanism that encourages initial demands closer to the target values will increase the likelihood of success.

Finally, the results suggest that a successful outcome is more likely the greater the expected disvalue of failure. The worse the parties see failure to address global climate change to be, the more likely they are to reach agreement. Similarly, an agreement is more likely the smaller the perceived costs of implementing the reductions necessary to reach commitments. For instance, technological developments leading to inexpensive low-emission energy sources may mean lower maximum demands as well as a greater willingness to consider higher amounts of reduction. Economic or political incentives could also influence the perceived payoff for successful agreement as well as the initial demands in negotiations, both of which could increase the chance of reaching a successful agreement. However, the model suggests that it is unlikely that small changes along these fronts will bring about solution feasibility. Rather, dramatic shifts would be required to significantly change likelihood of success. 


\section{References}

1. Finus, M. Game Theory and International Environmental Cooperation. (Cheltenham: Edward Elgar, 2001)

2. Gardiner, S. M. A Perfect Moral Storm. (Oxford University Press, 2011).

3. Barrett, S. Environment and Statecraft: The Strategy of Environmental Treaty-Making. (Oxford: Oxford University Press, 2003).

4. Decanio, S. J. and Fremstad, A. Game theory and climate diplomacy. Ecological Economics 85, 177-187 (2013).

5. Heitzig, J., Lessman K., Zou, Y. Self-enforcing strategies to deter free-riding in the climate change mitigation game and other repeated public good games. Proc Natl Acad Sci USA 108, 15739-15744 (2011).

6. Dietz, T. and Zhao, J. (2011). Paths to climate cooperation. PNAS, 108(38), 15671-15672 (2011).

7. Ostrom, E. Governing the Commons: The Evolution of Institutions for Collective Action. (Cambridge: Cambridge University Press, 1990).

8. Ostrom, E. Collective action and the evolution of social norms. Journal of Economic Perspectives, 14(3), 137-58 (2000).

9. Ostrom, E., Burger, J. Field, C. B., Norgaard, R. B., Policansky, D. Revisiting the commons: local lessons, global challenges. Science, 284: 278-82 (1998).

10. Samuelson, L. Evolutionary Games and Equilibrium Selection. (MIT Press, 1998).

11. Altamirano-Cabrera, J., Finus, M. Permit trading and stability of international climate agreements. Journal of Applied Economics, 9(1), 19-47 (2006).

12. Dellink, R., Finus, M., Olieman, N. The stability likelihood of an international climate agreement. Environmental and Resource Economics, 39(4), 357-377 (2007).

13. Finus, M., Altamirano-Cabrera, J., Van Ierland, E.C. The effect of membership rules and voting schemes on the success of international climate agreements. Public Choice 125(1), 95127 (2005).

14. Altamirano-Cabrera, J., Finus, M., Dellink, R. Do abatement quotas lead to more successful climate coalitions? Machester School, 76(1), 104-129 (2008). 
15. Finus, M. and Nr, D. Game theoretic research on the design of international environmental agreements: Insights, critical remarks, and future challenges. International Review of Environmental and Resource Economics, 2, 29-67 (2008).

16. Finus, M., Saiz, M. E., Hendrix, E. M. T. An empirical test of new developments in coalition theory for the design of international environmental agreements. Environment and Development Economics, 14(1),117-137 (2008).

17. Weikard, H., Dellink, R. Sticks and carrots for the design of international climate agreements with renegotiations. Annals of Operations Research, 1-20 (2010).

18. Santos, F. C., Pacheco, J. M., and Lenaerts, T. Evolutionary dynamics of social dilemmas in structured heterogeneous populations. PNAS, 103(9), 3490-3494 (2006).

19. Nash, J. The bargaining problem. Econometrica, 18(2), 155-162 (1950).

20. Kalai, E., Smorodinsky, M. Other solutions to Nash's bargaining problem. Econometrica, 43(3), 513-518 (1975).

21. Binmore, K. G., Game Theory and the Social Contract II: Just Playing. (MIT Press, Cambridge, MA, 1998).

22. Rubinstein, A. (1982). Perfect equilibrium in a bargaining model. Econometrica, 50(1), 97-109 (1982).

23. Muthoo, A. Bargaining Theory with Applications. (Cambridge University Press, 1999).

24. Young, P. An evolutionary model of bargaining. J. Econ. Theory, 59, 145-168 (1993).

25. Brown, G.W. Iterative solutions of games by fictitious play. In Activity Analysis of Production and Allocation, T.C. Koopmans (Ed.), (Wiley: New York, 1951).

26. Fudenberg, D., Levine, D. The Theory of Learning in Games. (MIT Press: Cambridge, MA, 1998).

27. Madani, K. Modeling international climate change negotiations more responsibly: Can highly simplified game theory models provide reliable policy insights?, Ecological Economics 90, 68-76 (2013).

28. Weischer, L., Morgan, J., Patel, M. (2012). Climate clubs: can small groups of countries make a big difference in addressing climate change?, Review of European Community \& International Environmental Law, 21(3), 177-192 (2012). 
29. Diringer, E. (2013). Climate change: A patchwork of emissions cuts. Nature, 501, 307309 (2013). 
Figure 1: The demands of three players (y-axis) during the initial rounds of negotiation (x-axis) from a characteristic example simulation where players converge on a feasible solution. Players are of equal size. $\delta=0.1$.

[Figure 2 - See Figure File]

Figure 2: The frequency of reaching a feasible solution ( $x$-axis) as a function of the number of players involved ( $y$-axis). $10^{5}$ simulations per data point, and all players are of equal size.

[Figure 3 - See Figure File]

Figure 3: The effect of introducing restrictions (r) on initial demands. When restrictions are placed on initial demands, such demands are drawn with uniform distribution from $[\delta+\mathbf{r}, 1]$ or $[\delta, 1-r]$ for restrictions on minimum demands or maximum demands respectively. When restrictions are placed on both maximum and minimum, initial demands are drawn from $[\delta+r, 1-r]$. Here $\delta=0.1$ with eight players of equal size.

Table 1: Frequency of success in an eight-player negotiation where players 1 and 2 are varied in size ( $s_{1}$ and $s_{2}$ ) making up an increasing proportion of global BAU. For these simulations $S_{1}=\mathbf{s}$, all other players were held at a constant size less than or equal to the first two players.

\begin{tabular}{|c|c|c|c|c|}
\hline Sum of $\mathrm{s}_{1}$ and $\mathrm{s}_{2}$ & $25 \%$ of BAU & $40 \%$ of BAU & $50 \%$ of BAU & $66 \%$ of BAU \\
\hline Freq. of success & 0.1982 & 0.2173 & 0.2885 & 0.6143 \\
\hline
\end{tabular}

Table 2: Average demand in successful agreements as a function of an agent's size. Results averaged among 5,414 successes of 10,000 simulations with six agents of varying sizes $(1,2, \ldots, 6)$.

\begin{tabular}{|l|l|l|l|l|l|l|}
\hline Agent size & 1.0 & 2.0 & 3.0 & 4.0 & 5.0 & 6.0 \\
\hline $\begin{array}{l}\text { Average final demand in } \\
\text { successful negotiations }\end{array}$ & $\approx 0.687$ & $\approx 0.606$ & $\approx 0.545$ & $\approx 0.510$ & $\approx 0.473$ & $\approx 0.426$ \\
\hline
\end{tabular}


Table 3. Success rates under different prior commitments in 10,000 simulations of eight agents, two of which comprise $25 \%$ of total player size each. Other agents are of equal size. The right column lists the success rate when the prior agreements are associated with a proportional increase in minimum demands.

\begin{tabular}{|l|c|c|}
\hline \multicolumn{1}{|c|}{ Scenario } & Success rate & With increased minimum \\
\hline Baseline (no prior reductions) & 0.2918 & 0.2918 \\
\hline $10 \%$ prior reduction from two largest & 0.3921 & 0.2533 \\
\hline $10 \%$ prior reduction from six smallest & 0.4440 & 0.3501 \\
\hline $5 \%$ prior reduction from all & 0.4063 & 0.2817 \\
\hline $20 \%$ prior reduction from two largest & 0.5480 & 0.2402 \\
\hline $20 \%$ prior reduction from six smallest & 0.7128 & 0.5303 \\
\hline $10 \%$ prior reduction from all & 0.5967 & 0.2874 \\
\hline
\end{tabular}

